\title{
Fabrication of Porous Titanium with Directional Pores for Biomedical Applications
}

\author{
Ji-Woon Lee ${ }^{1, * 1}$, Ji-Sun Lee ${ }^{1, * 1}$, Myoung-Gyun Kim² ${ }^{2}$ and Soong-Keun Hyun ${ }^{1, * 2}$ \\ ${ }^{1}$ Division of Materials Science and Engineering, Inha University, Incheon 402-751, Korea \\ ${ }^{2}$ New Materials Research Department, Research Institute of Industrial Science and Technology (RIST), Pohang 790-330, Korea
}

\begin{abstract}
A new fabrication method was developed for porous Ti with directional pores. Large sized-pores were generated by the evaporation of Mg wires, and small sized-pores were generated by sintering process. The porosity of the material was increased with increasing the number of wires and decreased with increasing sintering temperature and compact pressure. The diameter of large-sized pores was accurately same with that of $\mathrm{Mg}$ wire, and the diameter of small-sized pores was varied with the fabrication parameters showing similar trend to the porosity variation. The most advantageous point of the novel fabrication process is that the both porosity of the material and the diameter of the pores can be easily controlled by fabrication parameters, such as the number of wires, the sintering temperature and the compact pressure. The material can be used as possible bone implants possessing not only closer modulus to human bone, but also superior osteogenesis properties. [doi:10.2320/matertrans.MC201211]
\end{abstract}

(Received July 4, 2012; Accepted August 28, 2012; Published November 23, 2012)

Keywords: biomaterials, porous materials, sintering, titanium

\section{Introduction}

Titanium has been widely used as materials for orthopedic and dental implants because of their advantageous mechanical properties, corrosion resistance and biocompatibility. ${ }^{1,2)}$ In the materials currently used for surgical implants, $\mathrm{Ni}, \mathrm{Co}$ and $\mathrm{Cr}$ are released from stainless steel and $\mathrm{Co}-\mathrm{Cr}$ alloys, and $\mathrm{V}$ from Ti-6Al- $4 \mathrm{~V}$. ${ }^{3)}$ The toxic effects of these elements to the human body have been reported by Wapner. ${ }^{4)}$ Therefore, in the view point of biocompatibility, titanium is the most promising material for biomedical applications.

When an implant is much stiffer than the bone, a reduction in the bone mass adjacent to the implant occurs because an insufficient stress is transferred to the bone, resulting bone resorption adjacent to the implant. This phenomenon is known as "stress shielding effect" and leads to death of the bone cells. ${ }^{5)}$ A material with closer modulus to bone has to be used for implants to prevent this negative effect. The modulus of $\mathrm{CP} \mathrm{Ti}(100 \mathrm{GPa})$ is much closer to that of bone $(30 \mathrm{GPa})$ than other metallic biomaterials but still higher. Therefore, porous materials have been proposed for implant applications because they can reduce their modulus compared to inherent values. ${ }^{6}$

Optimal pore size that can facilitate bone ingrowth is in the range of 150 to $500 \mu \mathrm{m} .^{7-9)}$ There are several manufacturing processes for porous Ti-based materials. ${ }^{10-14)}$ These conventional methods, however, could not control the pore shape and its size. These pore characteristics are controllable for a manufacturing method using gas solubility gap between liquid and solid phase. ${ }^{15)}$ Although various porous metals with uniform pore shape and pore size can be fabricated by the above method, the pore shape and the pore size of porous Ti are not uniform because of high dissolving concentration of hydrogen. In this study, a new method for fabrication of porous $\mathrm{Ti}$ with directional pores is developed. We especially

\footnotetext{
${ }^{* 1}$ Graduate Student, Inha University

${ }^{* 2}$ Corresponding author, E-mail: skhyun@inha.ac.kr
}

focus on the uniformity of pore shape and its size. To achieve this, we used the vacuum sintering of $\mathrm{Ti}$ powders and the evaporation of $\mathrm{Mg}$ wires.

\section{Experimental Procedure}

First, commercially pure Ti powders (99.9 mass\%) with a particle size of $20 \mu \mathrm{m}$ and $\mathrm{Mg}$ wires $(99.9$ mass\%) with a diameter of $250 \mu \mathrm{m}$ were prepared to verify the formation of multi-sized pores. A stainless steel cylindrical disk of $8 \mathrm{~mm}$ in diameter and $4 \mathrm{~mm}$ in thickness was filled with the powders, and three wires were horizontally placed with the bottom of the disk into the powders, as shown in Fig. 1. Samples were then compacted at a pressure of 50,100 and $200 \mathrm{MPa}$ into the disk. Subsequently, sintering experiment was carried out in a vacuum $\left(7.5 \times 10^{-1} \mathrm{~Pa}\right)$ at 1273,1373 and $1473 \mathrm{~K}$. All compacts were heated to the sintering temperature at a heating rate of $10 \mathrm{~K} / \mathrm{min}$, held for $2 \mathrm{~h}$ and then furnace-cooled to room temperature.

Next, Ti powders (99.9 mass\%) with a particle size of $50 \mu \mathrm{m}$ and $\mathrm{Mg}$ wires with a diameter of $400 \mu \mathrm{m}$ were used to fabricate porous $\mathrm{Ti}$ with directional pores. We designed a new type of a mold made by stainless steel possessing holes placed at the side wall. Prismatic specimens $(10 \mathrm{~mm} \times$ $5 \mathrm{~mm} \times 30 \mathrm{~mm}$ ) were fabricated with this mold. Figure 2(a) shows the specially designed mold filled with $\mathrm{Ti}$ powders and $\mathrm{Mg}$ wires. The $\mathrm{Mg}$ wires were horizontally inserted

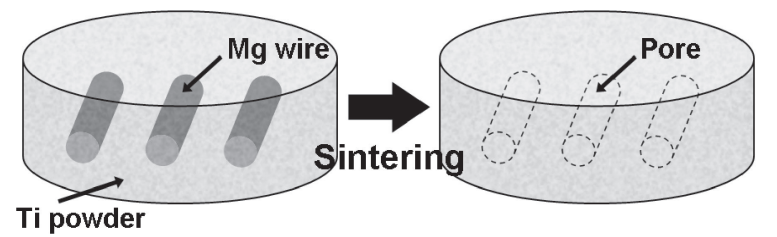

Fig. 1 Schematic diagram of the macro-pore formation in $\mathrm{Ti}$ compact during sintering process. Macro-sized pores are generated by the evaporation of the $\mathrm{Mg}$ wires. 

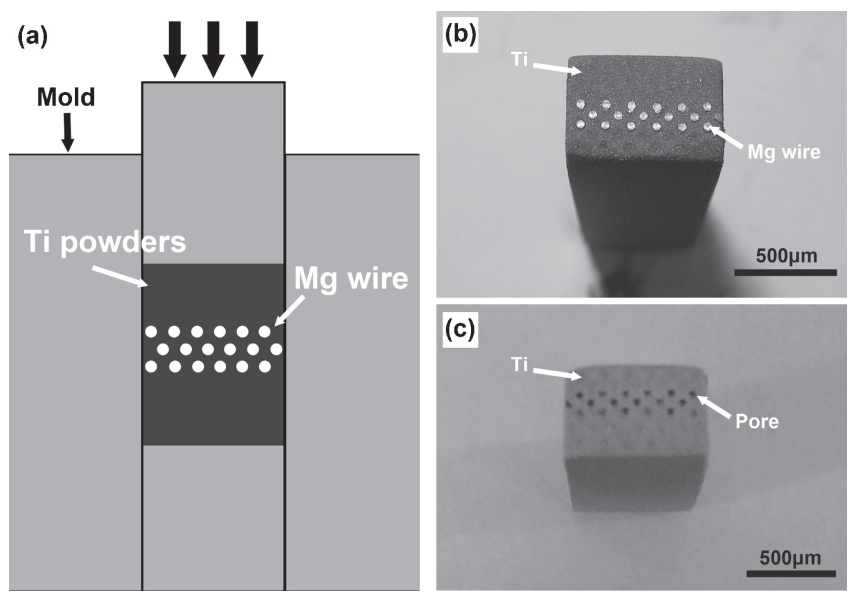

Fig. 2 (a) Schematic diagram of a specially designed mold for the fabrication of porous $\mathrm{Ti}$ and photograph of (b) a green body of prismatic Ti compact with inserted $\mathrm{Mg}$ wires and (c) porous Ti with macro-sized pores after sintering process. Macro-pores are generated by the evaporation of the $\mathrm{Mg}$ wires.

into holes on the side wall of the mold. Ti powders and $\mathrm{Mg}$ wires in the mold were compacted with a pressure of 100 and $200 \mathrm{MPa}$. Subsequently, sintering experiment was carried out in a vacuum $\left(7.5 \times 10^{-1} \mathrm{~Pa}\right)$ at $1473 \mathrm{~K}$. All compacts were heated to the sintering temperature at a heating rate of $10 \mathrm{~K} / \mathrm{min}$, held for $2 \mathrm{~h}$ and then furnace-cooled to room temperature.

Particle size distribution of Ti powders was measured by the particle size analyzer (Hydro 2000s, Malvern Instruments, Ltd., UK). The density values of the green compacts were determined by measuring the dimensions of the samples. The porosity of the sintered samples was measured using the relative density method. This relative density value was calculated by taking the theoretical value to be $4500 \mathrm{~kg} / \mathrm{m}^{3}$. The pore size was determined with the image analysis software (Image-pro plus, Media Cybernetics Inc., USA). The microstructure and the pore morphology of the porous samples were observed by scanning electron microscope (S-4300SE, Hitachi Ltd., Japan). The directional pore structure was observed by Micro-CT system (SMX-100CTSV, Shimadzu Corp., Japan). Each porous sample was polished and etched with Kroll's reagent. Atomic absorption spectroscopy (Aomalyst 400, PerkinElmer Inc., USA) was used to analyze the composition of the samples, especially whether $\mathrm{Mg}$ residuals were present or not.

\section{Results and Discussions}

\subsection{Verification of multi-sized pore formation}

Figure 3 shows the microstructure of porous Ti fabricated by vacuum sintering in a stainless steel disk. Two types of the pores were found in the specimens after sintering. Small sized-pores (hereafter micro-pore) were found in the entire of the specimens, and large sized-pores (hereafter macro-pore) were partially found in the specimens. The diameter of the macro-pore was $250 \mu \mathrm{m}$ same with that of $\mathrm{Mg}$ wire, and its morphology was cylindrical. The diameter of the micro-pore varied with the fabrication conditions, such as sintering temperature and compact pressure.

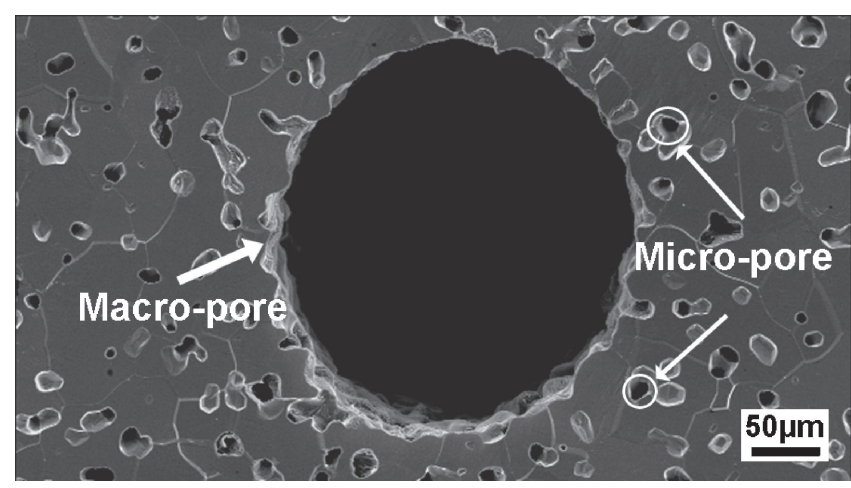

Fig. 3 Scanning electron micrograph of the pore structure for disk-type porous $\mathrm{Ti}$ fabricated by vacuum sintering. The white arrows indicate macro- and micro-pores. The diameter of the macro-pore is $250 \mu \mathrm{m}$.

Table 1 Porosity and micro-pore size of porous $\mathrm{Ti}$ fabricated by the vacuum sintering depending on the sintering temperature and the compact pressure.

\begin{tabular}{cccc}
\hline $\begin{array}{c}\text { Sintering } \\
\text { temperature, } \\
T / \mathrm{K}\end{array}$ & $\begin{array}{c}\text { Compact } \\
\text { pressure, } \\
p / \mathrm{MPa}\end{array}$ & $\begin{array}{c}\text { Porosity, } \\
P / \%\end{array}$ & $\begin{array}{c}\text { Micro-pore } \\
\text { size, } \\
D / \mu \mathrm{m}\end{array}$ \\
\hline 1273 & 50 & 42.7 & $19.4 \pm 8.4$ \\
& 100 & 38.7 & $18.9 \pm 7.8$ \\
& 200 & 33.3 & $18.8 \pm 9.6$ \\
1373 & 50 & 18.3 & $15.5 \pm 8.7$ \\
& 100 & 17.3 & $15.0 \pm 6.9$ \\
& 200 & 14.0 & $14.3 \pm 5.8$ \\
& 50 & 17.6 & $15.0 \pm 7.5$ \\
& 100 & 14.0 & $13.3 \pm 5.1$ \\
& 200 & 10.7 & $13.3 \pm 5.4$ \\
\hline
\end{tabular}

Figure 4 shows the microstructure of the micro-pores dispersed in porous $\mathrm{Ti}$ after sintering. The micro-pores were not clearly formed after sintering at $1273 \mathrm{~K}$. Above $1373 \mathrm{~K}$, the micro-pores were clearly formed at grain boundaries, and their shape was mostly irregular. Figure 5 shows the size of the micro-pores in porous Ti depending on sintering temperature and compact pressure, and the values are listed in Table 1. After sintering, the size of the micro-pores was decreased with increasing sintering temperature and compact pressure. At $1373 \mathrm{~K}$, the size was greatly decreased, and then its decrease was reduced up to the sintering temperature of $1473 \mathrm{~K}$.

Multi-sized pores were also found in the porous $\mathrm{Ti}$ specimens fabricated by vacuum sintering in the prismatic mold, as shown in Fig. 6. Macro-pores were partially located at where the $\mathrm{Mg}$ wires were placed before sintering process. The diameter of the macro-pore was $400 \mu \mathrm{m}$. Micro-pores, which were shown in the disk-type specimen, were found in the entire of the prismatic specimen. The size of the micropores was $12.2 \pm 6.0$ and $10.1 \pm 4.8 \mu \mathrm{m}$ with a compact pressure of 100 and $200 \mathrm{MPa}$, respectively.

Figure 7 shows micro-CT results of the prismatic porous specimen after sintering process. Pores were shown nearly at the same position in the images taken from the top to onethird of the specimen. This indicated that cylindrical pores were directionally aligned in the specimen. 

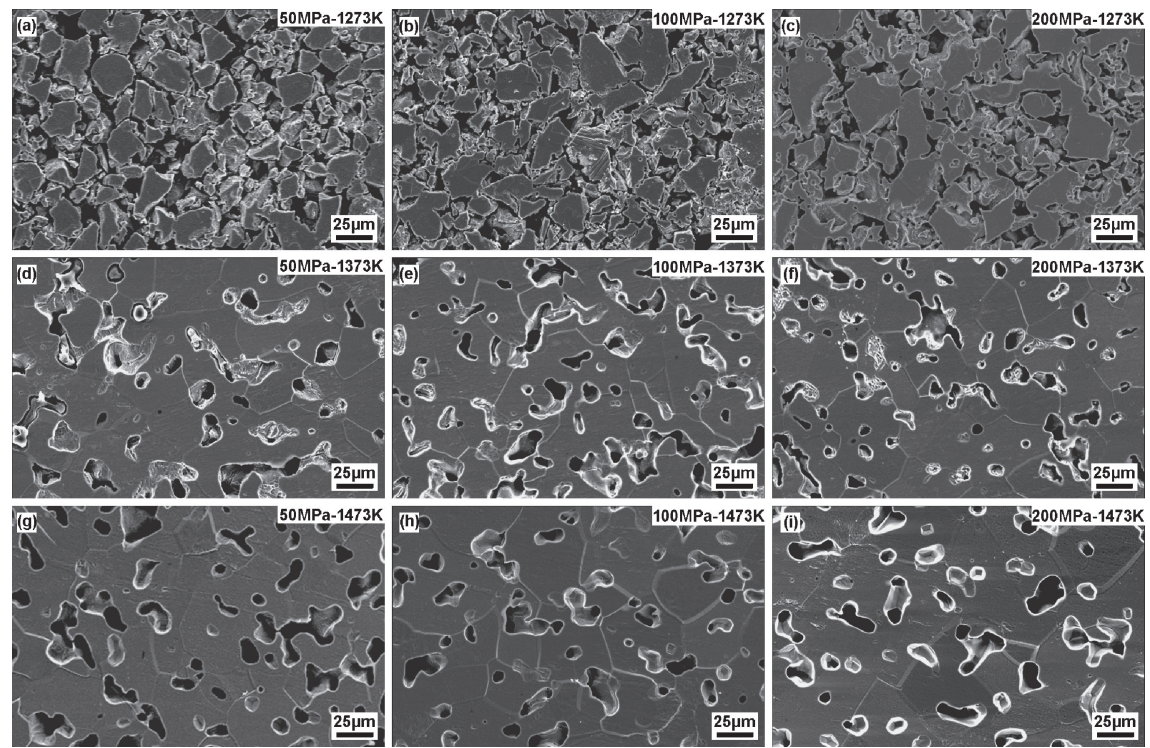

Fig. 4 Scanning electron micrographs of the microstructure for micro-pores dispersed in porous Ti after sintering at the sintering temperature of (a), (d), (g) $1273 \mathrm{~K}$, (b), (e), (h) $1373 \mathrm{~K}$ and (c), (f), (i) $1473 \mathrm{~K}$. The compact pressure was (a), (b), (c) $50 \mathrm{MPa}$, (d), (e), (f) $100 \mathrm{MPa}$ and (g), (h), (i) $200 \mathrm{MPa}$.

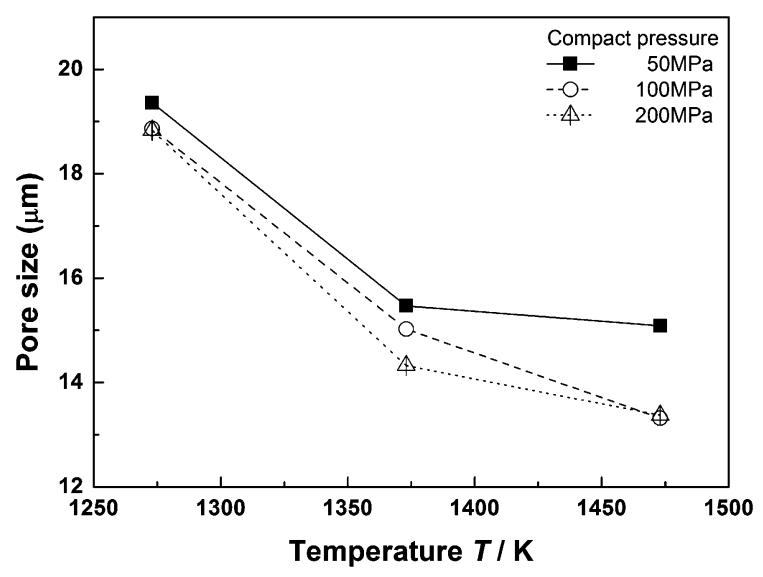

Fig. 5 Micro-pore size of porous Ti fabricated by the vacuum sintering depending on the sintering temperature and the compact pressure.
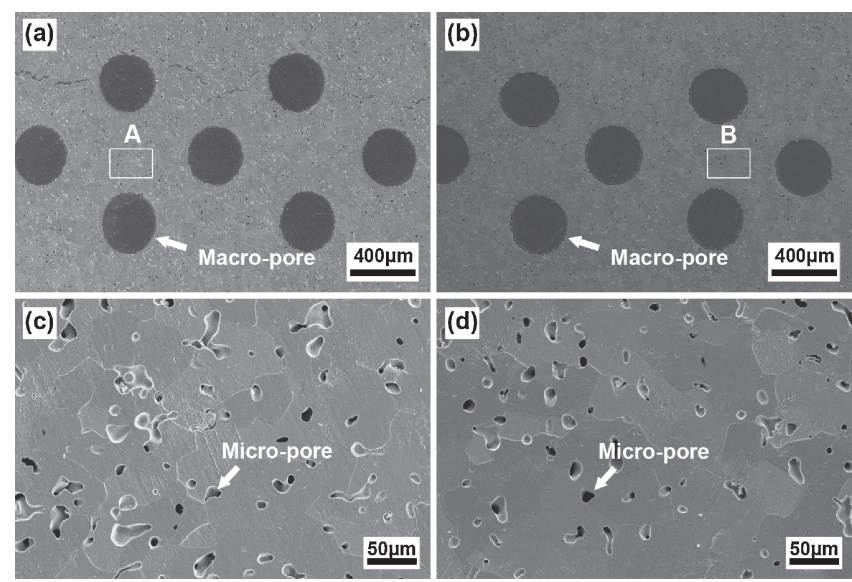

Fig. 6 Scanning electron micrographs of porous Ti fabricated by vacuum sintering with a sintering temperature of $1473 \mathrm{~K}$ and a compact pressure of (a), (c) 100 and (b), (d) $200 \mathrm{MPa}$ in a specially designed mold.
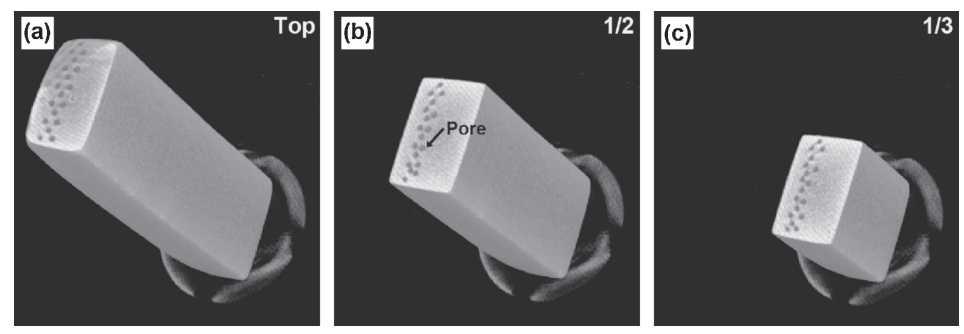

Fig. 7 Micro-CT images taken at the position of (a) top, (b) half and (c) one-third of porous Ti fabricated by vacuum sintering in a specially designed mold. Pore morphology is long and cylindrical as same as $\mathrm{Mg}$ wire.

In this study, the porous Ti possesses macro- and micropores. The macro-pores were formed at where the $\mathrm{Mg}$ wires were placed before sintering, and the diameter of the macropores in both disk-type and prismatic specimen was accurately same with that of the $\mathrm{Mg}$ wires, as shown in Figs. 3 and 6. From these results, it would be expected that the macro-pores are formed by the evaporation of the $\mathrm{Mg}$ wires during sintering.
$\mathrm{Mg}$ contents in the specimens are analyzed by atomic absorption spectroscopy (AAS), as shown in Table 2. AAS results showed that $\mathrm{Mg}$ contents in the specimen are less than that in Ti powders $(0.022$ mass $\%)$. Mg wire was entirely evaporated after sintering, owing to its equilibrium vapor pressure. The equilibrium vapor pressure of $\mathrm{Mg}$ at the relevant temperature can be calculated with the following equation: ${ }^{16)}$ 
Table $2 \mathrm{Mg}$ contents (mass\%) in the specimens analyzed by atomic absorption spectroscopy depending on sintering temperature and compact pressure. $\mathrm{Mg}$ contents (mass\%) in the starting material (Ti powders) was $0.022 \operatorname{mass} \%$.

\begin{tabular}{cccc}
\hline \multirow{2}{*}{$\begin{array}{c}\text { Compact pressure, } \\
p / \mathrm{MPa}\end{array}$} & \multicolumn{3}{c}{$\begin{array}{c}\text { Sintering temperature, } \\
T / \mathrm{K}\end{array}$} \\
\cline { 2 - 4 } & 1273 & 1373 & 1473 \\
\hline 50 & 0.0220 & 0.0008 & 0.0010 \\
100 & 0.0014 & 0.0008 & 0.0009 \\
200 & 0.0019 & 0.0014 & 0.0007 \\
\hline
\end{tabular}

$$
\begin{aligned}
\log p= & -\frac{7636}{T}+2.5 \log T-2.949 \times 10^{-3} T \\
& +0.874 \times 10^{-6} T^{2}+3.26
\end{aligned}
$$

where $p$ is vapor pressure and $T$ is temperature. At the testing pressure $\left(7.5 \times 10^{-1} \mathrm{~Pa}\right)$, the equilibrium temperature is $694 \mathrm{~K}$. The testing temperature was higher than $694 \mathrm{~K}$. Therefore, $\mathrm{Mg}$ is completely evaporated after sintering. Schematic diagram of pore formation in the sintering process is illustrated in Fig. 1. Although $\mathrm{Mg}$ might be still present in the implant, $\mathrm{Mg}$ will not generate the harmful effect on human body because of its biodegradable characteristics. ${ }^{17)}$

Micro-pores of the porous $\mathrm{Ti}$ in this study were formed at the entire of the specimens by sintering. Solid state sintering is usually divided into three stages - initial, intermediate and final. The initial stage follows the formation of necks between particles. During the intermediate stage, considerable densification occurs before isolation of the pores. The final stage involves densification from the isolated pore state to the final densification. ${ }^{18)}$ In this study, the micro-pores are formed in the following of three stages above. The diameter of the pores is influenced by the sintering variables, such as powder size, temperature, compact pressure, and so on. In this study, the diameter of the micro-pores is decreased with increasing sintering temperature and compact pressure.

\subsection{Porosity control}

Figure 8 shows the porosity of the porous Ti depending on compact pressure and sintering temperature, and the values are listed in Table 1. After sintering, the porosity of the Ti compacts was decreased with increasing compact pressure and sintering temperature. The porosity was $42.7-33.3 \%$ after sintering at $1273 \mathrm{~K}$. At the sintering temperature of $1373 \mathrm{~K}$, the porosity of the specimens was greatly decreased to 18.3 $14.0 \%$. The porosity was slightly decreased to $17.6-10.7 \%$ after sintering at $1473 \mathrm{~K}$.

Figure 9 shows the porosity of disk-type and prismatic porous $\mathrm{Ti}$ specimen with the compact pressure of 100 and $200 \mathrm{MPa}$. Measured porosity of the prismatic specimen was 19.1 and $15.9 \%$ for the compact pressure of 100 and $200 \mathrm{MPa}$, respectively. Furthermore, each porosity value of the prismatic specimen (eighteen wires) was compared with that of the disk-type specimen (three wires) at the same compact pressure. The porosity of the prismatic specimen was higher than that of disk-type specimen, and the difference in the porosity between the disk-type and prismatic specimen was 5 and $4.8 \%$ each at the same compact pressure.

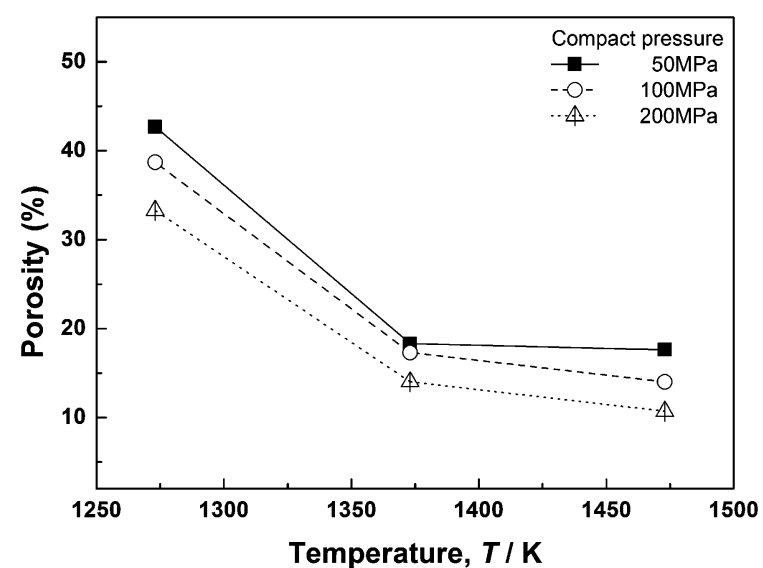

Fig. 8 Porosity of porous Ti fabricated by the vacuum sintering depending on the sintering temperature and the compact pressure.

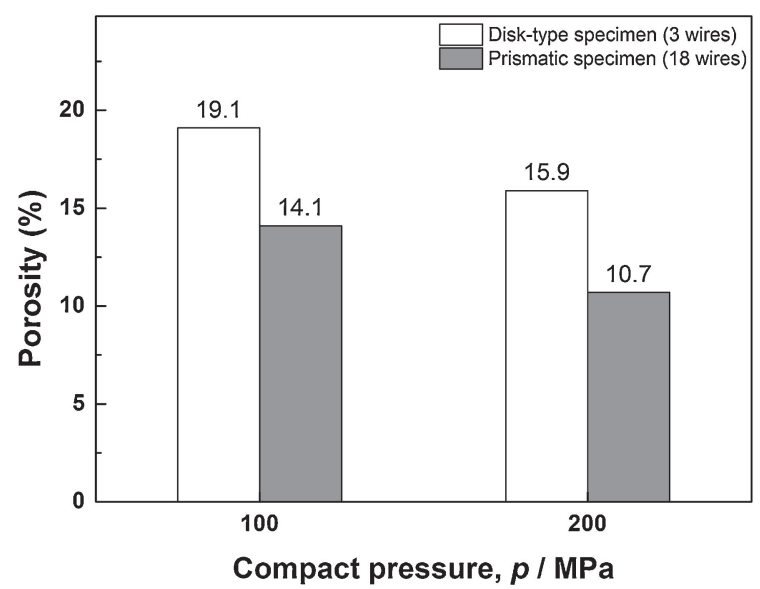

Fig. 9 Porosity of disk-type ( 3 wires) and prismatic (18 wires) porous $\mathrm{Ti}$ with directional pores fabricated by vacuum sintering with a compact pressure of 100 and $200 \mathrm{MPa}$.

One of the most attractive properties of porous metal as a biomaterial is that the modulus of the material can be reduced with increasing porosity. To avoid stress shielding of bone, an implant for human body should possess closer modulus to natural bone. The porosity dependencies of the porous materials to their modulus can be expressed by the following equation: ${ }^{15)}$

$$
E=E_{0}(1-p)^{m},
$$

where $E$ and $E_{0}$ are the moduli of porous and dense materials, respectively, and $m$ is the empirical constant. Boccaccini et al. ${ }^{19)}$ suggested that the empirical constant $m$ is related to the stress concentration around the pores in the porous material. When a porous material possesses cylindrical pores, it exhibits the mechanical anisotropy caused by the orientation of the pore axis. The reason for this was identified with the stress concentration differences depending on the direction of the pore axis. ${ }^{20)}$ When the direction of the pore axis is parallel to the applied stress, the empirical constant $m$ is usually known as 1 for the porous material with directional pores. Also, $m$ value is 3 for the material in this study with the pore axis perpendicular to the applied stress. ${ }^{21)}$ When the material is implanted to the human body 
to facilitate bone ingrowth, the modulus of the porous material is decreased with increasing porosity according to eq. (2).

The porosity of the porous $\mathrm{Ti}$ in this study can be mainly controlled by the number of the macro-pores. This type of pore is formed by the evaporation of $\mathrm{Mg}$ wires. Thus, the porosity will be increased with increasing the number of wires. The number of wires can be set as the target porosity is decided. Therefore, the modulus of the material can be controlled to reduce its mismatch between the human bone and the implant.

Total porosity of the porous Ti can also be controlled by the fabrication condition, such as compact pressure, sintering temperature and particle size of the initial material. At the same compact pressure, the porosity of the specimens is decreased with increasing sintering temperature. The amount of porosity decrease of the specimens sintered at between 1273 and $1373 \mathrm{~K}$ is higher than that of the specimens sintered at between 1373 and $1473 \mathrm{~K}$. At the same sintering temperature, the porosity of the specimens was decreased with increasing compact pressure. However, the porosity decrease caused by increasing compact pressure is not much higher than that caused by increasing sintering temperature. These indicate that the sintering temperature exhibits significant effect rather than compact pressure on the porosity of the specimens. Therefore, the porosity of the material can be controlled with these parameters.

The total porosity, $P$, of the porous Ti with directional pores in this study can be calculated with the following equation:

$$
P=P_{\mathrm{w}}+P_{\mathrm{s}},
$$

where $P_{\mathrm{w}}$ and $P_{\mathrm{s}}$ are the porosities caused by the evaporation of wires and by the sintering, respectively, and followed as

$$
\begin{gathered}
P_{\mathrm{w}}=\left(1-\frac{V_{\mathrm{w}} \times n}{V_{0}}\right) \times 100(\%), \\
P_{\mathrm{s}} \approx 5-10 \% \text { (experimentally determined) }
\end{gathered}
$$

where $V_{\mathrm{w}}$ and $V_{0}$ are the volume of wire and solid, respectively, and $n$ is the quantities of wires. The porosity caused by the sintering process is varied with the fabrication conditions, and followed by the previous studies. ${ }^{11,22-24)}$

\subsection{Availability of the porous $\mathrm{Ti}$ with directional pores as a biomaterial}

An ideal implant should possess similar mechanical properties to natural bone and should bond well with human tissue. As mentioned earlier, the optimal size of the pore for bone ingrowth is ranged between $150-500 \mu \mathrm{m}$. In this study, the diameter of the macro-pores in porous $\mathrm{Ti}$ is 250 and $400 \mu \mathrm{m}$ for disk-type and prismatic specimens, respectively. Therefore, the diameter of the pores fulfills for the bone ingrowth in this study. Furthermore, Higuchi et al. ${ }^{25)}$ suggested that pores with the diameter of $10-20 \mu \mathrm{m}$ allow only fibrous tissue to come into the pores, thus adding buffer to the stress. The fibrous connection is applied at the site of communication between implants and the external environment, enhancing physical binding strength. In this study, the diameter of the micro-pores is varied to $13.3-19.4 \mu \mathrm{m}$ with the fabrication condition. This will be advantageous for the bonding between the implant and the human tissue adjacent to the implant.

In the process we developed, the material possesses macroand micro-pores. The macro- and micro-pores will be utilized for bone ingrowth and fibrous tissue regeneration to add buffer to the stress, respectively. Especially, the macro-pore is long and cylindrical, thus, the bone ingrowth will be easier for the material in this study than other porous metals. In the animal experiment of Ref. 25), the osteogenesis was more active for cylinder type porous stainless steel than cubic type. This result indicates that the depth of the pores is also important criteria for pore shape affecting bone ingrowth.

Furthermore, the most advantageous point of the novel process is that the porosity of the material can be easily controlled by the number of wires, the sintering temperature and the compact pressure. The porosity of the material can be controlled to reduce the modulus mismatch between the implant and the human bone by adjusting the portion of macro-pores in the material, which is by controlling the number of $\mathrm{Mg}$ wires to be evaporated in this study. Also, the formation of the micro-pores can affect the porosity of the material by controlling the fabrication condition. This porosity controllability attributes that the modulus of the material can be set as closer to that of human bone from the reduction of the modulus mismatch. Therefore, the stress shielding phenomena in the human body can be minimized. Consequently, the osteocompatibility and the minimized negative effect of the implant (Stress shielding effect) can be achieved at the same time with the material fabricated by the novel process in this study.

\section{Conclusion}

In conclusion, we developed a new fabrication method of porous Ti with directional pores for biomedical applications. The conclusions in this study are presented in the followings.

(1) The porous $\mathrm{Ti}$ possessed macro- and micro-pores. The macro-pores with the diameter of 250 and $400 \mu \mathrm{m}$ were generated by the evaporation of $\mathrm{Mg}$ wires for disktype and prismatic specimen, respectively. The micropores with the size of $10-20 \mu \mathrm{m}$ were generated by sintering.

(2) The porosity of the material was decreased with increasing sintering temperature and compact pressure. The size decrease of the micro-pores showed a similar trend to the porosity decrease of the material. With the novel process, the porosity of the material can be simply controlled by changing fabrication parameters, such as the number of wires, the sintering temperature and the compact pressure and, thus, the modulus of the material can be obtained as closer to human bone.

We expect that the material fabricated by a new method can achieve not only active bone ingrowth from directional pores, but also active fibrous tissue regeneration to add buffer to the stress from small-sized pores. Therefore, this material can be used as promising bone implants in the viewpoint of similar modulus to the natural bone. Furthermore, the novel process contributes to widen the concept for the fabrication of the porous metals that can be used as biomedical applications. 


\section{Acknowledgments}

This work was supported by the Basic Science Research Program through the National Research Foundation of Korea (NRF) funded by the Ministry of Education, Science and Technology (2012007739), Inha University Research Grant and the Fundamental R\&D Programs for Core Technology of Materials funded by Ministry of Knowledge Economy, Republic of Korea (M-2009-01-0020).

\section{REFERENCES}

1) M. Geetha, A. K. Singh, R. Asokamani and A. K. Gogia: Prog. Mater. Sci. 54 (2009) 397-425.

2) O. E. M. Pohler: Injury 31 (2000) D7-D13.

3) Y. Okazaki and E. Gotoh: Biomaterials 26 (2005) 11-21.

4) K. L. Wapner: Clin. Orthop. Relat. Res. 271 (1991) 12-20.

5) D. R. Summer, T. M. Turner, R. Igloria, R. M. Urban and J. O. Galante: J. Biomech. 31 (1998) 909-917.

6) S. Kashef, W. Yan, J. Lin and P. D. Hodgson: Mod. Phys. Lett. B 22 (2008) 6155-6160.

7) S. F. Hulbert, F. W. Cooke, J. J. Klawitter, R. B. Leonard, B. W. Sauer and D. D. Moyle: J. Biomed. Mater. Res. 4 (1973) 1-23.

8) B. S. Chang, C. K. Lee, K. S. Hong, H. J. Youn, H. S. Ryu, S. S. Chung and K. W. Park: Biomaterials 21 (2000) 1291-1298.

9) A. I. Itälä, H. O. Ylänen, C. Ekholm, K. H. Karlsson and H. T. Aro: J. Biomed. Mater. Res. 58 (2001) 679-683.
10) I. H. Oh, N. Nomura, N. Masahashi and S. Hanada: Scr. Mater. 49 (2003) 1197-1202.

11) M. Bram, C. Stiller, H. P. Buchkremer, D. Stöver and H. Baur: Adv. Eng. Mater. 2 (2000) 196-199.

12) Y. Chino and D. C. Dunand: Acta Mater. 56 (2008) 105-113.

13) B. P. Lee, M. G. Kim, B. J. Choi, Y. J. Kim and S. K. Hyun: J. Korean Powder Metall. Inst. 18 (2011) 95-104.

14) I. H. Oh, H. T. Son, S. H. Chang, H. M. Kim, K. Y. Lee, S. S. Park and H. Y. Song: J. Kor. Inst. Met. Mater. 44 (2006) 441-445.

15) H. Nakajima: Prog. Mater. Sci. 52 (2007) 1091-1173.

16) F. F. Coleman and A. Egerton: Phil. Trans. R. Soc. A 234 (1935) 177204.

17) M. P. Staiger, A. M. Pietak, J. Huadmai and G. Dias: Biomaterials 27 (2006) 1728-1734.

18) S. J. L. Kang: Sintering-Densification, Grain Growth, and Microstructure, 1st ed., (Elsevier Butterworth-Heinemann, Oxford, 2005).

19) A. R. Boccaccini, G. Ondracek and E. Mombello: J. Mater. Sci. Lett. 15 (1996) 534-536.

20) S. K. Hyun, K. Murakami and H. Nakajima: Mater. Sci. Eng. A 299 (2001) 241-248.

21) S. K. Hyun and H. Nakajima: Mater. Sci. Eng. A 340 (2003) 258264.

22) O. M. Ferry, T. Ebel and T. Bormann: Mater. Sci. Eng. A 527 (2010) 1800-1805.

23) Y. H. Li, R. B. Chen, G. X. Qi, Z. T. Wang and Z. Y. Deng: J. Alloy. Compd. 485 (2009) 215-218.

24) Y. Torres, J. J. Pavon, I. Nieto and J. A. Rodriguez: Metall. Mater. Trans. B 42 (2011) 891-900.

25) Y. Higuchi, Y. Ohashi and H. Nakajima: Adv. Eng. Mater. 8 (2006) 907-912. 